TITLE:

\title{
BEHAVIORAL CONTROL SYSTEMS IN MEDUSAE; A COMPARISON BETWEEN HYDRO- AND SCYPHOMEDUSAE
}

\author{
AUTHOR(S): \\ Passano, L. M.
}

\section{CITATION:}

Passano, L. M.. BEHAVIORAL CONTROL SYSTEMS IN MEDUSAE; A COMPARISON BETWEEN HYDRO- AND SCYPHOMEDUSAE. PUBLICATIONS OF THE SETO MARINE BIOLOGICAL LABORATORY 1973, 20: 615-645

ISSUE DATE:

1973-12-19

URL:

http://hdl.handle.net/2433/175754

RIGHT: 


\title{
BEHAVIORAL CONTROL SYSTEMS IN MEDUSAE; \\ A COMPARISON BETWEEN HYDRO- AND SCYPHOMEDUSAE ${ }^{11}$
}

\author{
L.M. PASSANO \\ Department of Zoology, The University of Wisconsin, \\ Madison, Wisconsin 53706 U.S.A.
}

With Plate I and 10 Text-figures

\section{Introduction}

One of the several ways by which the behavior of an animal can be studied is to investigate the functional mechanisms controlling behavior. Most animals have specialized tissue-the nervous system-to receive, process, and store information about their environment, and to coordinate their motor activities. From the pioneer work of EIMER (1874) and RoMANES (1885) and many subsequent investigations (see BuLlOCK and HoRRIDGE, 1965), we know that coelenterates too have nervous tissue and that it is a major element in the coordinating and control system of the medusaform members of this phylum. Detailed knowledge of how it functions, of its components and pathways, coding systems, synaptic sites, pacemakers, et cetera would be a step toward clarifying how behavior is effected in these animals.

It is also evident that coelenterate behavioral control is not solely restricted to the nervous system. MACKIE (1965) has shown that epithelial tissue without nerves, whether cellular or syncytial, can transmit signals from one part of the animal to another. Such epithelial conduction is integrated with the nervous system in hydromedusae such as Sarsia (MACKIE et al., 1967; MACKIE and PASSANO, 1968). It may be the major element of the coordination machinery of hydrozoan polyps (for example, see KASs-Simon, 1973).

Certainly for coelenterates the study of behavioral control mechanisms must be approached with as few preconceptions and as broadly as possible. The necessity for this approach is shown by what little is already known from the phylum. It is unwise to construct hypothetical control mechanisms for coelenterates based on the known neurophysiology of higher animals, for different systems can be and are utilized in different organisms for the same behavior (PANTIN, 1950).

1) I would like to thank Elizabeth BRAUER for critically reading this paper and for her many suggestions towards clarifying my ideas, some of which I have followed. Linda MCCoNNELL helped greatly by typing my manuscript. I wish also to thank my Department and the Graduate School for financial aid towards the cost of attending the Symposium. 
The "medusa is the completely evolved coelenterate" (HyMAN, 1940a). Since this morphotype occurs in both Scyphozoa and Hydrozoa, and has since the beginning of the fossil record in the lower Cambrian half a billion years ago, it is worth while comparing the behavioral control mechanisms of these two types of jellyfish. In both overall behavior and general biological roles they show an amazing similarity considering their long history of independent, if parallel, evolution. In both, nervous control predominates. Their effector systems are comparable, but closer examination of a representative species from each class shows notable differences in the way in which these two kinds of medusae exert control. Hydromedusae exhibit a more advanced level of organization, characterized by greater "central" development, multiple interactive pacemakers and a larger number of differentiated conduction pathways. This higher level of physiological attainment is paralleled by a more elaborate nervous structure and a larger behavior repertoire. This difference between the two groups of medusae is qualitative as well as quantitative. Epithelial conduction is not found in scyphomedusae, and, perhaps for related reasons, surface recording with fine suction electrodes is very difficult from these forms. A beginning has now been made in recording intracellularly from both classes (PATTON and PASsANo, 1974; MACKIE, 1973). Present evidence suggests that there may be a fundamentally different conduction method in scyphomedusae not found in hydrozoa. We have found that giant fiber nerve-net (GFNN) neurons fail to show the familiar all-or-none, nondecremental action potentials known both from other Metazoa and from the giant fibers in the stem of the siphonophore hydrozoan, Nanomia (MACKIE, 1973).

In this paper I intend to summarize several years of work which I have carried out on medusae with many collaborators, including, at various times (and in alphabetical order): Mari-Luz Hernandez-Nicaise, George MaCkie, Coyla MCCullough, Kari Passano, Marion Patton, Max Pavans de Ceccatty, David Potter and Jean Beetham Smith. The work was commenced at the University of the West Indies, Kingston, Jamaica, then at the Station Zoologique, Université de Paris, Villefranchesur-mer (A.-M.) France, for many summers at the Friday Harbor Laboratory of the University of Washington, and recently at the Virginia Institute of Marine Sciences, Gloucester Point, Virginia. I would like to acknowledge the hospitality and assistance of these laboratories, their directors and their staffs. Support for this work has been received from the GuGGENHEIM Foundation, N.S.F. Grant GB27669, N.I.H. Grant NB6009, and the Graduate School of the University of Wisconsin.

\section{Natural History of Sarsia}

Sarsia tubulosa (M. SARS) is a common Anthomedusa occurring in Northern European, North American Atlantic and Pacific littoral waters in the late spring and into mid-summer. At Friday Harbor it is one of the most abundant species, dominating the inshore plankton from early May until July. It buds off from a coryne-type 
hydroid at about $1 \mathrm{~mm}$ diameter, then quickly grows to full size and sexual maturity in a matter of weeks, often exceeding $14 \mathrm{~mm}$ diameter at the bell margin while the four extended tentacles may each be over $160 \mathrm{~mm}$ long (Plate I).

The duration of the medusa stage of this life history is not known precisely; however, it seems unlikely to last more than 100 days in the waters near Friday Harbor. Rearing the medusa in the laboratory has been achieved (WERNER, 1965) but in my experience it takes longer than comparable growth in Nature. Thus far no behavioral changes have been noted between the small, newly liberated jellyfish and the largest collected, a range in size from less than $1 \mathrm{~mm}$ diameter to nearly $20 \mathrm{~mm}$, except for the well-known inverse correlation between swimming beat frequency and bell size which occurs in all medusae. Otherwise the smallest and the largest (and thus youngest and oldest) Sarsia show the same behavioral repertoire of intermittent swimming, feeding, and the "crumple" escape reflex.

The typical swimming behavior of Sarsia consists of trains of swimming contractions of all four quadrants of striated subumbrella ectodermal muscle sheets, interspersed with intervals of relaxation of varying duration. Each coordinated muscle contraction works against the elastic skeleton of mesogloea (GLADFELTER, 1972) to which the muscles are presumably attached. At night especially, and when undisturbed, such bouts of swimming often may consist of 10 to 30 or more contractions, with the bout lasting a minute or two, followed by 5 minutes or so quiescence. Plate I, A shows the appearance of the medusa as it floats motionlessly in the water column, with its four tentacles held away from the body, and they and the pendulous manubrium are fully extended in a relaxed position. The tentacles in the relaxed state are held out from the bell to form this sort of "elbow" but trail out behind the bell during swimming (Plate I, B).

A forthcoming swim bout is often, but not invariably, indicated by the near simultaneous twitch-shortening of all four tentacles. The first swimming movement then follows a perceptible pause. The tentacles continue to contract in a coordinated manner, independently of the swimming contractions, while the latter go on with increasing strength for the first half dozen beats. Eventually the swimming rate decreases, with individual contraction amplitude inversely proportional to the intercontraction interval, and tentacles start to relax (Plate I, B) so that they then stream out behind the moving medusa. They are often fully extended when the main bout is finished.

During the day, or in a light-adapted animal in the laboratory (for no light independent circadian rhythm has been detected), swimming bouts tend to be long-lasting affairs continuing for hundreds of successive swimming contractions. Swimming frequency is a measure of excitation level. Usually daytime swimming frequency is lower than that occurring in the shorter, periodic swim bouts of the dark-adapted or nocturnal animal. Another swim pattern often seen consists of a few swimming contractions ( 3 to 6 ) interrupted by brief quiscent periods of about the same time 
duration, this sequence reoccurring again and again.

In general, manubrial shortening is not correlated to swimming activity, even to the extent shown by the tentacles. In Sarsia tubulosa the manubrium characteristically extends well below the velum irrespective of the state of elongation of the tentacles and is not always affected by swimming activity. It is only during the "crumple" escape response, described below, that manubrium and tentacles show fully coordinated shortening. Yet in conditions that promote rapid swimming the manubrium is usually contracted, as are the tentacles.

The feeding sequence starts with chance contact by the nematocyst-armed manubrium or tentacles with an active prey organism such as a copepod. If it is caught on the manubrium, the mouth seeks out the struggling prey and engulfs it, but if it is caught on a tentacle, it must be transferred to the mouth. The incidence of swimming contractions increases during this time, and the tentacle or tentacles concerned both shorten and are pulled inward towards the manubrium by contractions of the radial subumbrellar muscles proximal to those tentacles concerned. Actual contact between tentacle-held prey and manubrium occurs by chance, but once it is made, the mouth seeks out the prey and engulfment commences. Swimming is then almost entirely suppressed (Plate I, D) (Hernandez-Nicaise and Passano, 1967). The sum total of this behavior suggests several semi-autonomous parts of the medusa-each tentacle, the swimming effectors, the manubrium, and the mouth-carrying on independent activity yet capable of interacting with each other.

A very similar feeding behavior has been found in the closely related $S$. princeps (HAECKEL) by FRASER (1969). His observations differ in three significant details from ours (Hernandez-Nicaise and Passano, 1967) on S. tubulosa. He found that the mouth at the end of the pendalous manubrium extends towards the lifted and inwardly held tentacle, whereas we observed only that the mouth made seeking movements after contact with the tentacle had been made. Secondly, he found that "Pulsations usually continue in vigorous bursts during the feeding process...". In $S$. tubulosa swimming contractions are usually suppressed (at least in calm conditions) during the transfer process from tentacle to stomach. Finally he reports that: "If different food organisms become attached to more than one tentacle at the same time, only one lifts, the others continuing to trail until the mouth has injested the food from the first tentacle. The second then lifts and the mouth extends to meet it, the meeting being very accurately accomplished." We observed more autonomous activity by each tentacle, although two (or even three) holding the same prey showed coordination of movements occasionally (as if the coordination were by the temporary mechanical linkage). We never observed tentacles "taking turns" at the mouth.

The overriding of such limited regional independence is shown even more in the escape reaction of Sarsia, the "crumple" response (Hyman, 1940b). Crumpling is found in many, if not most, hydromedusae. It is a rapid, maximal shortening of tentacles and manubrium with the contracted tentacles tucked into the subumbrella 
by the simultaneous contraction of all of the radial muscles, the contraction of the circumferential marginal muscles and the cessation of swimming. The resultant spherical form reduces the effective surface to volume ratio which may let the jellyfish sink more quickly because of its reduced drag (Plate I, C). Crumpling characteristically ends with a sustained bout of swims.

The crumple response is another example of coordination between manubrium, tentacles and swimming effectors, but it is more extreme than feeding in that it involves all of the tentacles and all quadrants of the radial muscles. It is in addition quite labile (which would seem appropriate for escape reflexes in general, as in giant fiber mediated responses in annelids and decapod crustaceans) and can be initiated by moderately strong multiple stimuli to any part of the animal, including the exumbrella. It overrides swimming and feeding behavior.

To summarize the behavior of Sarsia: to a considerable degree, it is a federation of separate entities. Each tentacle can show coordinated activity separate from the others-even portions of a single tentacle can act autonomously. The manubrium usually is independent of tentacles and swimming and the tidal ebb and flow of the endodermal coelenteric canals goes on quite independently of the "outer" behavior. Only the swimming effectors, the striated subumbrellar muscles and the associated velar muscles, usually act as a unit, and even there the velar twitches may occur in the absence of swimming contractions. Yet some behaviors require greater integration between the various parts of the animal, and here Sarsia shows subordination of local autonomy to the common good.

\section{Natural History of Two Scyphomedusae}

Two species of scyphozoan jellyfish have been studied in detail. Cyanea capillata (L.) is a semaeostome medusa widely distributed in northern boreal seas. It can grow to an exceedingly large size, but animals of 5 to $20 \mathrm{~cm}$ diameter were used in this study. A variety (possibly a separate species; CALDER, personal communication) from the Chesapeake Bay has also been used. The animal usually maintains itself in the upper levels of the water by regular rhythmic swimming contractions of the subumbrellar coronal and radial muscles, letting the tentacles, arranged in horseshoe-shaped clusters between the eight rhopalia, stream out with the diaphanous elongated lips.

According to Russell (1970) the two British species of Cyanea feed on hydromedusae, ctenophores, and other plankters. In the Chesapeake I noted small fish and polychaetes in their coelenterons. FrASER (1969) found Cyanea omnivorous in the laboratory; he suggested that they may be an important predator on larval fish.

Swimming frequently, as is general in medusae, varies inversely with size. An animal $15 \mathrm{~cm}$ in diameter may show a swimming rate of 20 to 30 per min while maintaining itself near the surface. The animal (at least in the daytime) shows long, moreor-less regular bouts of swimming contractions which can maintain it near the water 
surface. Often it also shows intermittent sinking, at least to below two meters depth, so that its progress with the tidal current consists of a sawtooth-like path in the upper part of the water column, slowly rising to close to the surface and then rapid sinking. This sort of alternation may reoccur over and over with a periodicity of two to five minutes.

Occasionally and especially after gross stimulation the animal actively swims downward, and I have observed long continual swims against the bottom of deep jars in captive individuals. Usually the body conformation keeps the medusa upright. According to FR̈̈NKeL (1925; summarized in RUSSELL, 1970), when the animal is tilted the uppermost coronal muscles go into a state of tonic contraction and do not fully relax, thus lessening their effectivenss in comparison to the rest of the swimming muscles and permitting the animal to resume its normal position.

Strong stimuli usually cause the jellyfish to increase the frequency of swimming, often doubling the rate of contraction. When trying to net them from the surface they may rapidly sink out of range, but whether this is effected by turning and downward swimming, or some other sort of response, is not known. In moderate tidal currents at Friday Harbor or the Chesapeake Bay, Cyanea essentially swims against the current, laterally.

In the laboratory illumination increases the contraction frequency a small but significant amount (in spite of an absence of discrete pigmented spots on the rhopalia). The animals also frequently rest on the bottom of aquaria; it is not known whether they show comparable behavior in Nature or whether this laboratory behavior is a response to the abnormal and deleterious conditions of captivity.

The other species studied in detail, Cassiopea xamachana R. P. Bigelow, is a specialized rhizostome, mostly sessile in habit, common in many shallow bays, mangrove inlets, coral lagoons, etc., in the West Indies. Closely related species are found throughout the tropics. Cassiopea usually occurs lying on sandy to muddy-sandy bottoms oral side uppermost, oral arms extended above the subumbrellar surface. The rather languid "swimming" contractions of the peripheral coronal, circumferentially arranged, muscles which graduate into the inner, radially arranged, muscles set up food currents through the finely subdivided oral arms which are perforated by the multitudinous "mouths". As in Cyanea, the peripheral muscles of the subumbrella contract first, followed later by the more central muscle. But in Cassiopea there are no outer radial muscles; the radially arranged blocks are inner to the main circular muscles. The direct result of this reversed arrangement of muscles, compared to Cyanea and many other scyphomedusae, is that the initial circular contraction raises the outer edge of the jellyfish directing the subsequent main jet of water up through the mouth arms.

As noted subsequently, this contraction sequence is due to the greatly increased duration of the neuromuscular delay period for the more central muscles of both species, following a single motor nerve impulse to the entire subumbrella. 
Particles of food are stung by nematocysts as required, trapped by mucus and carried in mucus food strings to one of the many mouths on the arm upper surface. The medusa actually swims through the water only after it is disturbed and even then it soon recovers its oral-up posture, settles down on the bottom again, and continues its essèntially sessile existence.

Both scyphomedusae show slow movements of longer duration of the oral arms or mouth frills independent of swimming contractions. Some of these movements are local, some involve one entire lip or mouth arm, as in feeding, while others are slow coordinated responses that may involve the entire oral apparatus. Cassiopea can also show a cleaning reflex involving mouth-arm lifting and shortening, if sand or other debris falls on the oral surface; a similar response frequently occurs along with enhanced swimming movements that actually lead to swimming, when Cassiopea is disturbed by touch or prodding. Such responses are an order of magnitude slower than single swims, lasting one to several minutes in all.

\section{The Behavioral Physiology of Sarsia}

The functioning of the nervous and other control mechanisms, and of the relevent effector mechanisms, was studied in order to understand the physiological basis of the behavior of the animal. It is convenient as before to summarize first that of the hydromedusan Sarsia and then consider the scyphomedusae. We must bear in mind the differences as well as the similarities between these representative members of the two classes of medusae, especially with regard to the nervous system. Sarsia has a marginal nerve ring lying just inner to the marginal ring canal. It is made up of a number of nerve fibers (ca 200; MACKIE, 1969) arranged in two bundles separated by the mesogloea layer that extends out into the velum, separating the circular and radial ectodermal velar muscles. The neurites and occasional cell bodies that make up the nerve ring lie at the base of the ectoderm cell layer, immediately over the mesogloea. Circumferentially they connect the four (in Sarsia) tentacle bulbs where there are concentrations of nerve cell bodies and neuropile called the "tentacular ganglia" (MACKIE, 1969), and where there are connections between fiber bundles overlying the radial canals ascending to the manubrium, the optic nerves from the ocellus and the ectodermal nerve plexus of the tentacle. Here also endodermal epithelial pulses make functional contact with the ectodermal nervous elements (MACKIE et al., 1967; MACKIE and PASsano, 1968).

There has been speculation (Horridge, 1955; Bullock and Horridge, 1965) concerning the functional roles of the two nerve rings in hydromedusae. The outer (or upper) nerve ring may be assigned a sensory role while the inner (or lower) is either called mixed sensory and motor or solely motor in function. There is no experimental evidence for these assignments and experimental attempts to section one nerve ring without damage to the other have not been successful. These assumptions remain 
logical but unproven. MACKIE's (1969) view of the nerve rings as “... tracts connecting the four ganglia. .." and his demonstration and the work of others (see MACKIE, 1969) that there is a heterogeneity in the size classes within the outer ring makes it likely that each ring subserves several functions, making the terms "motor" and "sensory" inappropriate.

Elsewhere, over the striated subumbrellar muscle fibers, in the manubrium and down the tentacles, fine multipolar neurons form ectodermal plexuses. However, these neurons do not extend entirely across the subumbrellar quadrants, nerves have not been found on the outer radial muscle side of the velum, and are not known from the exumbrellar epithelium. Even when neurites overlie the coronal muscles of the inner velum and the subumbrella, there are no neuromuscular specialized endings found.

The ocellus is briefly described by MACKIE (1969) as consisting of a knot of distal processes of the receptor cells separated from their cell bodies by a cup of cells with black pigment granules. The "lens" structure of the ocellus is actually made up of these distal processes. The proximal neurites of the receptor cells form two optic nerves which pass around either side of the tentacle in the nematogenic tissue of the tentacle base and then enter the tentacular ganglion close to the point of emergence of the outer nerve ring. These fibers are presumably purely sensory in function. They have not been traced further than their entrance to the ganglion (but see below).

It was early discovered that it is surprisingly easy to record electrical signals from hydroids (JOSEPHSON, 1961, 1962); the same is true of hydromedusae when fine tipped flexible suction electrodes of drawn-out polyethylene tubing are employed (PASSANo, 1965). Such suction electrodes permit long term recording from partially restrained pieces of medusae or even from entire jellyfish.

Two types of electrical pulses can be routinely recorded from the marginal nerve ring area of Sarsia (and from many other hydromedusae, both antho- and leptomedusae). Both are through-conducting without evident decrement at approximately $50 \mathrm{~cm}$ per $\mathrm{S}$ velocity at $21^{\circ} \mathrm{C}$. Both occur spontaneously as well as following appropriate electric stimulation. Both can be correlated to behavioral events.

The first pulse type is termed marginal pulses or margin pulses (PASSANO, 1965; Passano et al., 1967; Hernandez-Nicaise and Passano, 1967; Mackie and Passano, 1968), abbreviated as "MPs". They originate in the proximal part of the tentacles, or in the tentacle bases, and are most easily recorded from either of these sites. It has not been possible to record them from the tentacular ganglion, however. MPs can be seen (Fig. 1, top trace) to show size facilitation that is independent of the site of origin of the pulses, so that a pulse originating in one of the four tentacle bulbs and spreading circumferentially to another, will facilitate the size of a second MP originating in the latter site.

Cutting the nerve rings blocks the conduction of MPs from one tentacle bulb to the next, which support the notion suggested by the high (for coelenterates) conduction 

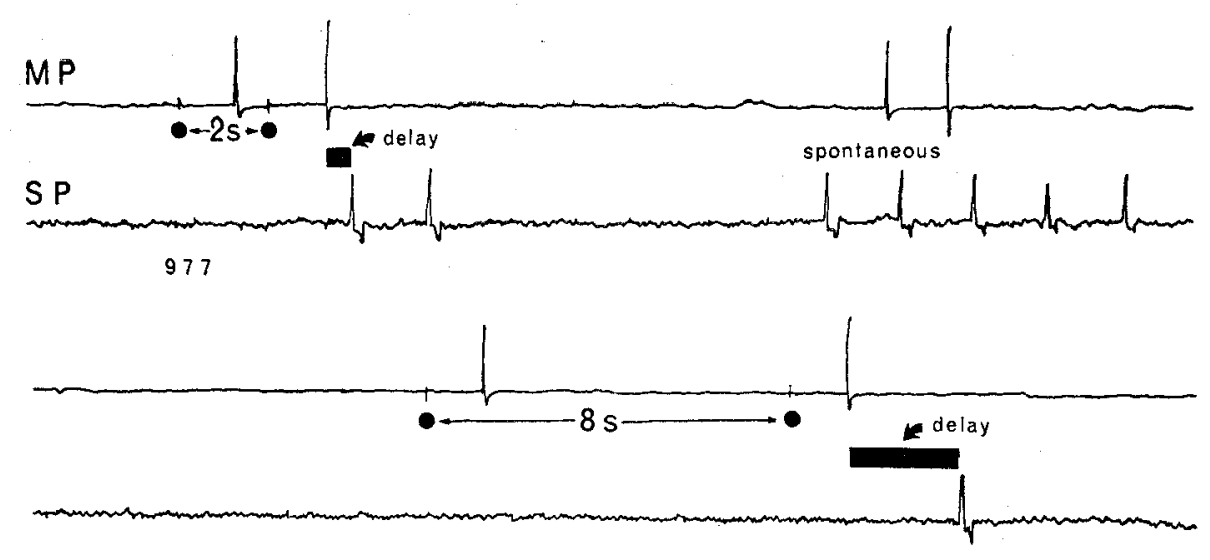

978

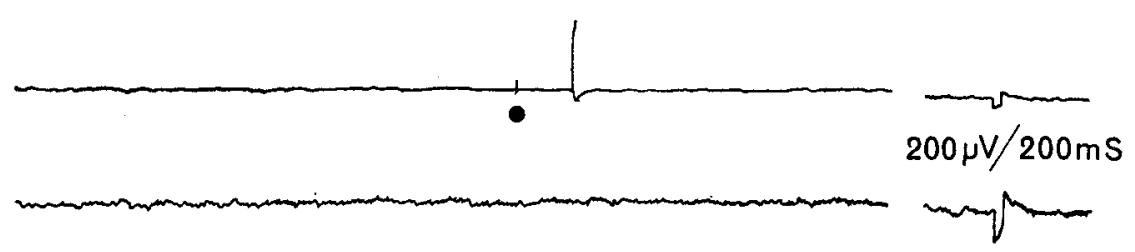

Fig. 1. Sarsia. Swim pulse initiation by paired margin pulses. Continuous record; upper trace (MP) shows induced and spontaneous margin pulses recorded from the tentacle base; lower trace (SP) shows swim pulses from the nerve ring. are stimulus artifacts from shocks to tentacle tip, $2 \mathrm{~S}$ apart, $8 \mathrm{~S}$ apart and a single shock.

velocity of $50 \mathrm{~cm}$ per $\mathrm{S}$ that MPs are conducted by nerves. Yet recording them is actually easier from the tentacle where the nerve plexus is not as dense than on the marginal nerve ring. To quote JosePHSON's (1961) perceptive comment with regard to the hydroid Cordylophora: "The size of the potentials. . and the ease with which they can be recorded are not what one would expect from a diffuse nerve net... The explanation for the large size of the pulses probably lies in the summing of simultaneous potentials from a number of elements in a system held in synchrony because of the activity of lateral connections".

In other words, many neurons of the nerve net are acting together. With the recent recognition of epithelial conduction in Hydrozoa, another possible explanation is that the passage of the MP triggers a response in the cells of the overlying epithelium. In fact, whatever the basis of the easily recorded pulses in Hydrozoa, they are certainly a boon to the study of the behavioral physiology of these animals.

Single MPs are not associated with any effector response. To this extent, then, they are "cryptic"; it is impossible to infer their occurrence by observing the responses of the organism or preparation. But MPs often come in pairs 50 to $200 \mathrm{mS}$ (and sometimes as close as $20 \mathrm{mS}$ ) apart. A single MP from one pacemaker can also induce a second MP in another tentacle after a similarly short interval. When paired pulses 
occur, whatever their origin, the tentacular ectodermal epithelial muscle sheet contracts, so that the tentacle twitches throughout its length. A subsequent single MP will cause a further, larger contraction to this facilitated tentacle. A burst of MPs will cause full tentacle shortening of all four tentacles. I have not measured the maximum interval between MPs that still permits tentacle response, but it is my impression that it is much shorter than the maximum time permitting response facilitation at the SP pacemaker, possibly 3 or $4 \mathrm{~S}$ rather than 8 to $10 \mathrm{~S}$ at the pacemaker.

An important feature of the MP system is its ongoing endogenous activity, often at a frequency too low to cause direct tentacular response. Under some recording conditions Sarsia shows extraordinarily regular long series of MPs. These bouts may be caused by some unspecified stress placed on the preparation; at lower temperatures, for instance, the MP bursts are likely to be shorter, more patterned (starting slowly, speeding up and then declining in frequency to half the maximum shown before stopping), and regularly intermittent.

In partially immobilized Sarsia preparations of marginal nerve ring, tentacle bulbs, tentacles and some of the coronal muscle, the more-or-less regular, endogenous MPs come from a restricted region of the tentacle base just below the ocellus and (possibly) on either side of the outer midline. No distinctive nervous structure has been described from this area, but it has a dense ectodermal nerve-net while there is little ectodermal muscle there. MPs do not originate from the tentacular ganglion.

The second pulse type recorded from the marginal nerve ring is the swim pulse (or "SP") (PASSANO, 1965). It is also recorded from the tentacular ganglion, the upper or coronal muscle side of the velum and the coronal subumbrellar swimming muscles. On the velum and the subumbrella the pulse has two components (MACKIE and PASSANO, 1968, Fig. 5B); the second component, which is the more labile component with $\mathrm{Mg}^{++}$anaesthesia, is absent from SPs recorded over the nerve ring or from the tentacular ganglion. Presumably this second component is directly associated with muscular contraction.

SPs are also conducted rapidly $(50 \mathrm{~cm}$ per $\mathrm{S})$ around the margin when the marginal nerve ring is intact. Slow conduction $(8.5 \mathrm{~cm}$ per $\mathrm{S}$ ) occurs around the demarginate subumbrella muscle. In Sarsia (but not in other hydromedusae; MACKIE, personal communication) such excitation spread is limited to a single quadrant of the organism; it does not spread across the radial muscle ectodermal epithelium which overlies the four radial canals.

SPs only originate from the marginal tissue, but the precise location of SP pacemakers has not been determined. In fact, there is an indication that there are many loci-many potential pacemakers - centered around the marginal nerve ring at each of the four tentacle bases. This would indicate that the tentacular ganglion is the area of the pacemakers, but: 1) there is some suggestive, but by no means conclusive, evidence that SP pacemakers are not restricted to these four ganglia but can be found along the marginal nerve ring; 2) no physiological evidence for pacemaker activity was 
found even with extensive microelectrode probing of the ganglion; 3) the expected concurrent recording of MP and SP pulses (due to MP action on the SP pacemaker, see below) was not realized from the ganglion. These findings appear to preclude the tentacular ganglion as the SP pacemaker site. Thus, in the case of the SP pacemaker near the tentacle bulb, there is no specific pacemaker cell or structure responsible for all of the pulses; there is an apparent redundancy of pacemakers, yet the SP system is integrated into a unit, and does show very characteristic features as a whole.

In my description above of the behavior of undisturbed Sarsia, it was noted that swimming bouts may be preceded by a coordinated tentacle twitch, or even several twitches. Recordings of the electrical activity of the margin show a corresponding, characteristic pattern of bouts of SPs being just preceded and accompanied by bouts of MPs. The occurrence of a pair of MPs (either from one or from two tentacle bases with the second firing in response to the first) seems to initiate the first SP after a characteristic time delay of half a second or so. Unless conduction of MPs is an order of magnitude slower to SP pacemakers than around the nerve ring $(50 \mathrm{~cm}$ per $\mathrm{S})$, this delay must reflect the time required for the arriving MP to induce a propagated SP from the pacemaker; as such, variations in the length of the "delay" are a quantitative measure of pacemaker state.

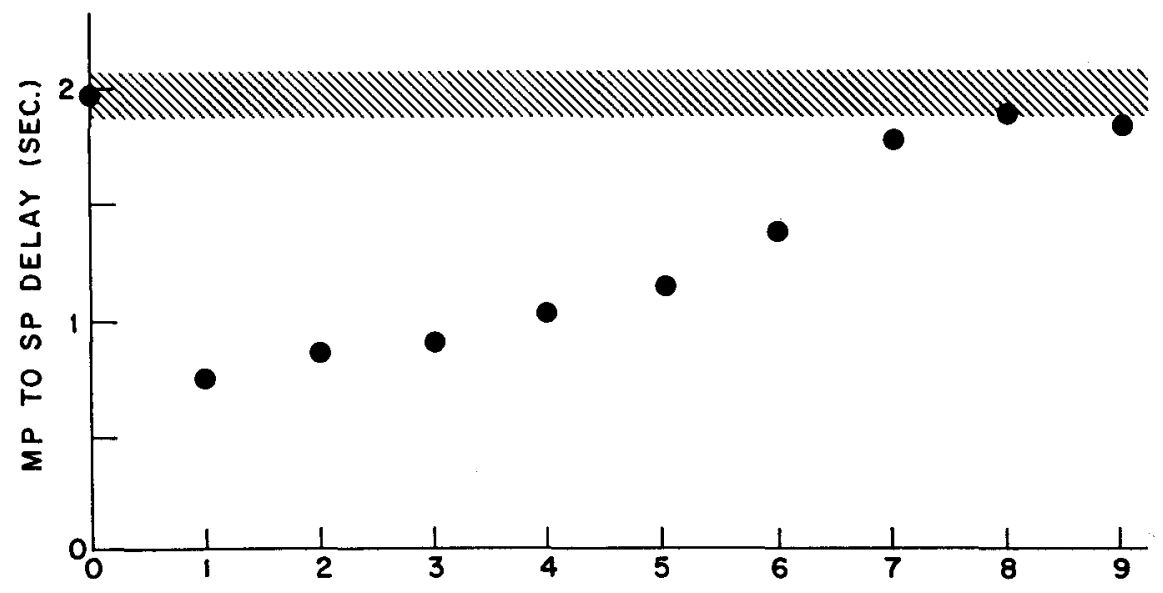

INTERVAL BETWEEN FACILITATING AND EFFECTIVE MPS (SEC.)

Fig. 2. Sarsia. Swim pulse "delays" (see text) following paired margin pulses. Point at zero interval is the mean delay for effective single margin pulses; standard deviation of this mean value is shown by the horizontal band.

This interpretation of delay variability is greatly strengthened by the finding that delay times are directly correlated to the interval between pairs of MPs. An example of this is shown in Fig. 1, and data for one particular experiment involving 201 trials are summarized in Fig. 2. It can be seen that this preparation was showing some SP firing after single MPs induced by electrical stimulation to the tentacle tip, as well as 
many SP responses following pairs of MPs. Figure 2 shows clearly that the delay to a pair of MPs given 1 to $5 \mathrm{~S}$ apart is half the length of delay to a single MP. What is not shown by this graph, but which also indicates the differences between the responses to single and paired MPs, is that the percentage of such induced SPs rises from $15 \%$ for single MPs to over $99 \%$ for the pairs. Even after the delay times lengthened to the single pulse value, for pairs 8 or $9 \mathrm{~S}$ apart (Fig. 1, center record) the percentage responses were $78 \%$ and $33 \%$ respectively. A further difference between the responses to one or a pair of MPs was that the incidence of multiple (two or three) SPs induced also greatly increased. Multiple SP responses were very uncommon to single MPs, less than $1 \%$. They went to $70 \%$ for pairs of MPs $1 \mathrm{~S}$ apart, $84 \%$ for pairs $2 \mathrm{~S}$ apart (example shown in Fig. 1, upper record left), $81 \%$ for $3 \mathrm{~S}$ pairs, $56 \%$ for $4 \mathrm{~S}$ pairs and still $27 \%$ for pairs of MPs 5 S apart. Multiple firing is rare with MP pairs of over 5 $\mathrm{S}$ interval. Therefore, in brief summary: SP pacemakers in Sarsia preparations can be relatively unresponsive to single MPs, yet very responsive to pairs of MPs 1 to $9 \mathrm{~S}$ apart. Delay times are reduced for pairs $6 \mathrm{~S}$ apart and less; multiple firing is most likely to occur for MP pairs 2 to $3 \mathrm{~S}$ apart. Each parameter of MP effectiveness shows a somewhat different pair interval optimum.

There are notable differences between different Sarsia preparations or even between the same preparation at different times. In some experiments SP responses occur regularly to single MPs. Occasionally preparations do not respond consistently even to paired MPs, although this is less common. Frequently "spontaneous" SP firing without MP input is such as to obscure any MP sensitivity of the pacemakers. SP pacemaker state, therefore, is not a fixed quality but is variable in time as well as between different loci.

Dark-adapted Sarsia frequently respond to illumination by starting a bout of swimming contractions; this SP pacemaker response is a reasonably reliable criterion to differentiate SPs from MPs, for the latter are inhibited by such stimulation. A train of SPs can also be stopped by turning off the light. Attempts to localize the photoreceptors involved were not entirely conclusive. The four ocelli are the primary photoreceptors, but some photic responsiveness was still evident after they had been excised. It is possible that this coelenterate, as in Hydra (Passano and McCullough, 1962, 1963), shows some pacemaker light sensitivity without the participation of a discrete photoreceptive structure.

Extremely low level spike activity has been recorded from the marginal nerve ring near the tentacle bulbs, from the bulbs, and from the tentacle ganglion region, following both "light on" and "light off" stimulation. Morphologically, MACKIE and his collaborators (MACKIE, 1969) have traced the optic nerve to these regions. I have not yet been able to achieve consistent recording of these nerve impulses.

The SP pacemakers may also be inhibited by impulses originating near the mouth and conducted the length of the manubrium and down the subumbrella along the radial canals to the margin. These pulses, termed "swallowing pulses" (HeRnANDEZ- 
NiCAISE and PASSANO, 1967), occur only while food objects are being engulfed. It is suspected that these are conducted in the endoderm. The inhibition can be overridden by other stimulation, however.

There is no evidence for direct feedback of SP output on the MP system, and even indirect mechanical stimulation of the tentacles caused by the swimming movements does not seem to be commonplace, although it may occur. However, MP pacemakers can be triggered by local tentacle contractions, and are also excited by an "incoming" MP from another tentacle base. An example of such MP recruitment is seen following the fourth and fifth stimuli in the experimental trial shown in Fig. 3. Here, in a two
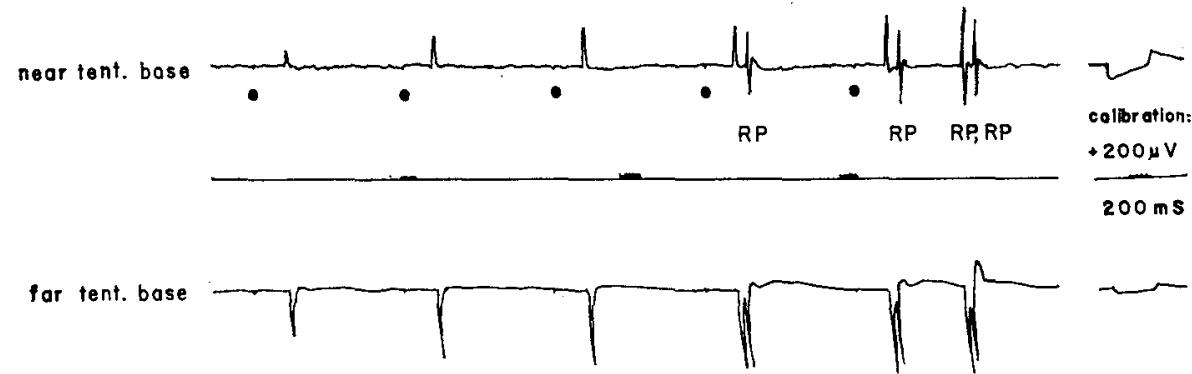

Fig. 3. Sarsia, two tentacle preparation. A train of induced margin pulses (1.5 Hertz) from the "near" tentacle tip shows size facilitation, echo firing from other tentacle base, radial pulse (RP) initiation and repetitive MP firing. MP's recorded negative-going on upper trace, positive-going on lower trace; time in seconds on center trace; stimulus escape indicated by on upper trace.

tentacle preparation, induced MPs cause, on the fourth stimulus, a second MP at the other (or "far") tentacle base. The latter $\mathrm{M}$ is then conducted back to the near tentacle. The same thing occurs on the fifth shock as well, and then a spontaneous MP $350 \mathrm{mS}$ later from the near tentacle base causes still another such "echo" MP.

Echo firing in the MP system is important because it produces the pairs of MPs needed to cause tentacle contractions. Any such contraction involving more than one tentacle requires such pairs. But paired MPs can also emanate from a single tentacle, often repeated over and over for minutes at a time. We have even observed examples of MP firing in triplets. Such double (and triple) firing is very effective in stimulating SP pacemakers.

Multiple MPs can stimulate still another response component of Sarsia, one involving the ectodermal radial muscles of the subumbrella. These relatively slow muscles cause the tentacle to be pulled up and inward towards the manubrium, and are utilized both in the feeding response and the "crumple" escape reflex. A small rather slow electrical pulse can be recorded from the tentacle base (Fig. 3) and an enhanced pulse can be obtained from over the radial muscle directly. These pulses are called here "radial pulses" (RP) for convenience, but it should be emphasized that 
they are not conducted from one radial muscle to another, or elsewhere in the animal. In the example shown (Fig. 3) they occur in both quadrants although they are best recorded in the upper trace (as a downward, positive) deflection. RPs are only elicited after several ( 3 or more) MPs occur, and then seem to require a rapid pair of MPs such as those provided by echo firing or more intense tentacle stimulation.

In the normal behavior of Sarsia, individual radial contractions are the rule, yet MPs are through-conducted around the entire margin and reach all four quadrants. Thus it seems likely that something additional must be required for radial muscle contraction, something that is restricted to one quadrant. Possibly an endodermal

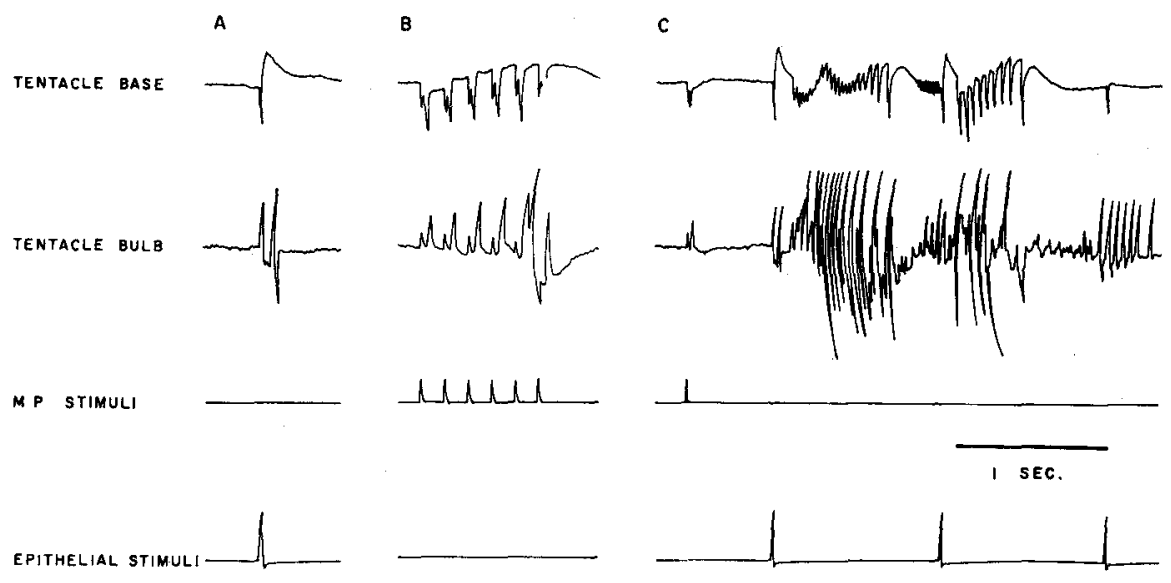

Fig. 4. Sarsia. The crumple response. Upper two traces are response records, lower two traces record stimulation. A. Endodermal epithelial pulse following electrical stimulus to exumbrellar ectoderm. B. Six MP's induced by stimulus train to tentacle tip. C. Crumples initiated by single epithelial pulses following one MP. (Note stimulus escape artifacts on recording channels.)

epithelial pulse is initiated by the electrical stimulation of the tentacle tip (or by a struggling copepod impaled on the tentacle) which synergizes with the MPs much as exumbrellar ectodermal epithelial pulses synergize with MPs in the crumple (Fig. 4). Yet it has been shown (MACKIE et al., 1967; MACKIE and Passano, 1968) that in the crumple the epithelial pulse passes from exumbrellar ectoderm to subumbrellar endoderm; this pathway should thus connect the ectoderm to radial muscles of all quadrants and would not allow radial responses by single quadrants alone. We must look elsewhere for the control that permits single radial contractions.

The crumple response clearly involves all of the animal and results from the synergistic response of subumbrellar muscles (radial and coronal), tentacles, velum, manubrium and the sphincter muscle outside the margin. The reflex is protective. It is also very labile.

We have shown (MACKIE et al., 1967) that the crumple requires two separate 
inputs, an MP followed by an epithelial pulse. Figure 4A shows the arrival of an epithelial pulse at the tentacle bulb following an electrical stimulus given to the exumbrellar ectoderm. Stimulus escape ("shock artifact") is recorded at the base of the tentacle. Figure 4B shows the response recorded at both tentacle base (top record) and tentacle bulb (second from top) to a train of 6 electrical stimuli given to the tentacle (third line of record). Figure $4 \mathrm{C}$ shows the paroxysmal response to a single MP followed by a slow train of 3 epithelial pulses. Violent repeated contractions start about $50-100 \mathrm{mS}$ after each epithelial pulse. Note, however, that the response recorded at the tentacle base is slower after the second epithelial pulse and absent entirely after the third. There is still a response to the third epithelial pulse from the bulb, but it is weak. The crumple response quickly adapts out, although MP and epithelial pulse are still conducted as usual. The biological advantage of such quickly adapting escape reflexes is obvious, but the mechanism for this adaptation is not known. It does not appear to be sensory, but rather "central".

\section{The Behavioral Physiology of Scyphomedusae}

In his recent volume on British scyphomedusae, RuSSELL (1970) provides an admirable summary of the morphology of these jellyfish relevant to their behavior, so that there is no need to include this here. The main distinctions differentiating scyphomedusae are twofold: 1) they possess eight (usually) marginal bodies called rhopalia, where there are concentrated various sensory receptors, and from which pacemakers periodically cause swimming movements; 2) scyphozoans do not have a marginal nerve ring, but instead have two separate nerve-net coordinating systems, the giant fiber nerve-net (GFNN) conducting motor impulses over the subumbrellar striated swimming muscles, and the diffuse nerve-net (DNN) extending over all of the subumbrellar ectoderm, tentacles, mouth arms and lappets. A similar endodermal nerve-net of unknown function is found in the coelenteric epithelium (PASSANo and PASSANO, 1971) and may be continuous with the DNN.

The functional distinction of the two nerve-nets is complete. RomanEs (1885) clearly demonstrated the existence of two conduction pathways which interact only at the marginal rhopalia, and both indirect experimental evidence and finally direct electrical recording from the two nerve-nets has confirmed this fact (see PASSANO, 1965). But the morphological distinction between the two nerve-nets remains a problem. MAYER (1910, page 500) says: "The exumbrellar nerve-ring, found commonly in hydromedusae, does not exist in the scyphomedusae, but is replaced by a subumbrellar plexus of fibers extending between the marginal sense-organs and also radially inward from these ganglionic centers. There is also a diffuse, nervous, epithelial, ectodermal network over the subumbrellar." Yet it was only in 1956 that HORRIDGE (1956a) was able to demonstrate conclusively the morphological distinction between the two nets in the ephyra larva, naming them the "giant fibre system" and the "diffuse nerve-net". 
These terms are used here, although in his definitive overview of invertebrate nervous systems, BULlOCK (BULlOCK and HoRRIDGE, 1965) writes of the "large bipolar cell net" and the "small multipolar cell net". With most scyphomedusan material it is not yet possible to make clear anatomical distinction between the two nerve-nets where they coexist, for the size ranges overlap (K.N. Passano, personal communication). I have also not been able to record from the DNN with microelectrodes as yet.

Recording electrical signals from scyphomedusae is much more difficult than from hydromedusae, yet it is possible to record from immobilized preparations with suction electrodes, or with agar-filled glass pipettes placed near a rhopalium. The events usually recorded (in successful cases) are slowly rising compound pulses of various shapes, but usually of consistent shape for a specific spot and for pulses traveling in a specific direction. In the example shown (Fig. 5) DNN pulses are larger than GFNN pulses, but this is not usual.
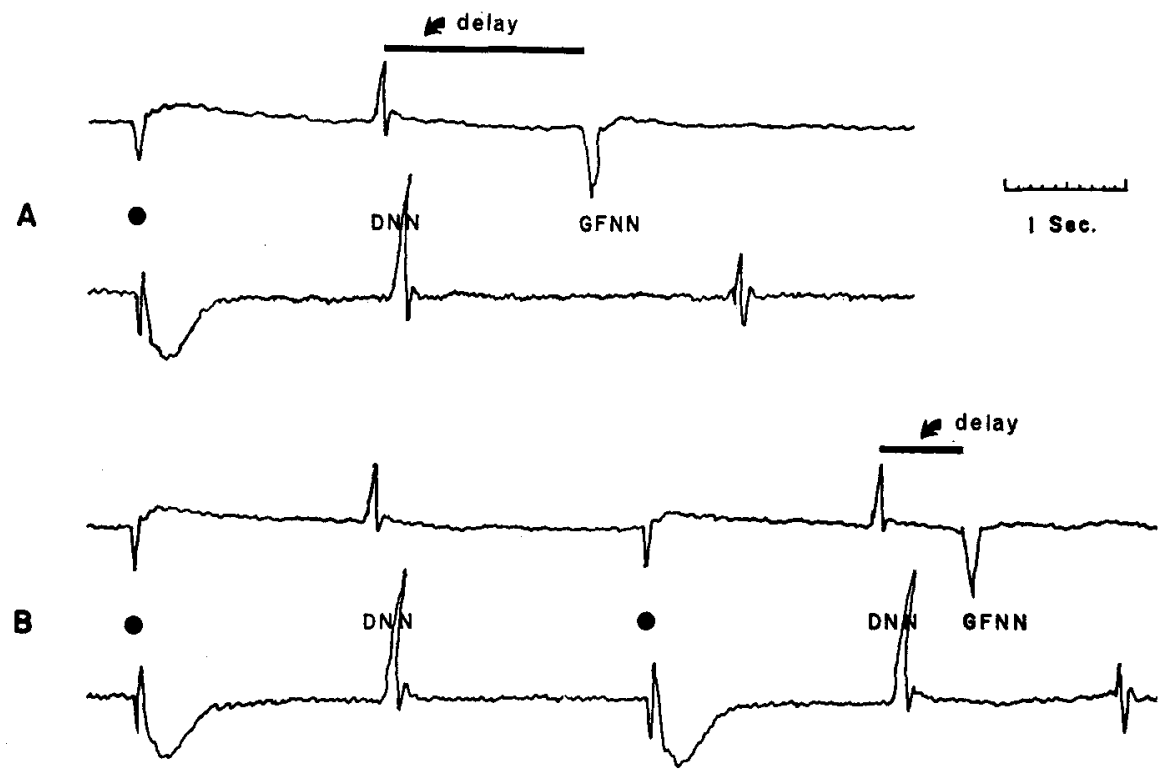

Fig. 5. Cassiopea, two rhopalia preparation (see text). A. Single effective DNN pulse from electrical stimulus (o), inducing GFNN pulse from upper trace marginal ganglion after typical delay. B. Paired DNN pulses $4.2 \mathrm{~S}$ apart induce GFNN pulse from same ganglion after short delay.

In the preparation generally used (PASSANO, 1965) all of the rhopalia save two adjacent were removed, the margin was cut away and the oral apparatus and central tissue excised, leaving a hollow ring of coronal muscle. This was then cut through between the two rhopalia into a long strip and pinned to a wax-lined dish. Recording electrodes were positioned near the base of each now terminal rhopalium and stimulating electrodes placed elsewhere on the tissue. By stimulating on an area without 
GFNN, or by using an isolated block of tissue connected only by a DNN conducting "bridge" (margin, or oral tissue), one can induce single DNN pulses coming to the two GFNN pacemakers (Fig. 5).

Several criteria exist to differentiate the two pulse types that are recorded where the GFNN and the DNN are superimposed. DNN pulses are through-conducted across the subumbrellar ectoderm at $15 \mathrm{~cm}$ per $\mathrm{S}$, in contrast to the $45 \mathrm{~cm}$ per $\mathrm{S}$ conduction velocity of the GFNN pulses (PASSANO, 1965). It may be noted that in the experiment recorded in Fig. 5 with a preparation cut from a Cassiopea about $22 \mathrm{~cm}$ in diameter the GFNN pulse was transmitted from the upper trace recording site to the lower trace recording site (about $60 \mathrm{~cm}$ apart) in $1.3 \mathrm{~S}$, giving a conduction velocity of $46 \mathrm{~cm}$ per S. A DNN pulse initiated by an electric stimulus near the margin slightly less than half way between the two recording sites took $1.9 \mathrm{~S}$ to reach the upper trace electrode and $2.1 \mathrm{~S}$ to travel the other direction to the lower trace electrode, or a total of $4 \mathrm{~S}$. Ignoring time for pulse initiation, and a slightly longer conduction pathway, this pulse then shows a conduction velocity of $15 \mathrm{~cm}$ per $\mathrm{S}$.

The pulses are of different shape (although not usually as extreme as seen in Fig. 5). GFNN pulses only come from the marginal ganglia at the rhopalia, whereas DNN pulses can originate "spontaneously" from anywhere else on the subumbrella, as well as from the tentacles and the manubrium. Of course, GFNN pulses are followed by a contraction of the striated subumbrellar muscle; DNN pulses produce no response (in Cassiopea and Cyanea) by this muscle tissue.

MAYER (1906) discovered and popularized the "entrapped circuit wave" preparation in a ring of Cassiopea subumbrella devoid of marginal ganglia. The wave is the muscle response to a single GFNN pulse transmitted in a single direction continuously around a complete ring of tissue which is long enough to permit the muscle to regain excitability between, the circuit of the GFNN pulse. Such entrapped pulses frequently conduct for many hours, or even days (MAYER, 1910).

HoRRIDGE (1956b) noted MAYER's (1906) observation ..."That the amplitude of the contractions increased for a short time after a general mechanical disturbance,"... in such a ring preparation, and correctly surmised that this effect demonstrates the existence of two separate conduction pathways. His experimental evidence showed that DNN excitation is responsible for the transient amplitude increase. In Cassiopea the DNN pulse facilitates the muscle response to a subsequent GFNN pulse for as long as $12 \mathrm{~S}$ (PASSANO, 1965), even though it can cause no muscle response directly.

It is curious that it has not been possible to demonstrate an "entrapped wave" by a DNN pulse, even though such pulses "through-conduct" on the subumbrellar ectoderm.

GFNN pulses are easier to elicit by stimulation and easier to record. In immobilized preparations, they continue to occur spontaneously from the marginal pacemakers, although probably at a reduced rate comparable to unrestrained preparations. DNN pulses less commonly occur under these experimental conditions; 
their occurrence seems erratic and not from localized pacemaker sites. They do not come from the marginal ganglion.

As with the SP pacemaker of Sarsia, the GFNN pacemaker of scyphomedusae is notably variable in its responsiveness. Often consistent responses are not obtainable, and it is usual in two rhopalia preparations for the pacemakers to differ in their responsiveness. Nevertheless the delay interval (or marginal delay or simply "delay"), the time between the arrival of an exciting DNN pulse at the margin and the appearance of a GFNN response, is a quantitative measure of pacemaker state.

Figure 5A shows the pacemaker from the site closest to the upper trace's electrode causing a single GFNN pulse $1.6 \mathrm{~S}$ after the arrival of a single DNN pulse. As noted in the graph shown as Fig. 6 , this is a typical delay value $(1.55 \pm 0.05 \mathrm{~S})$ for Cassiopea responses to single DNN pulses when they occur. But when they do not occur after a single DNN pulse, GFNN pulses will almost always be triggered by a pair of pulses.

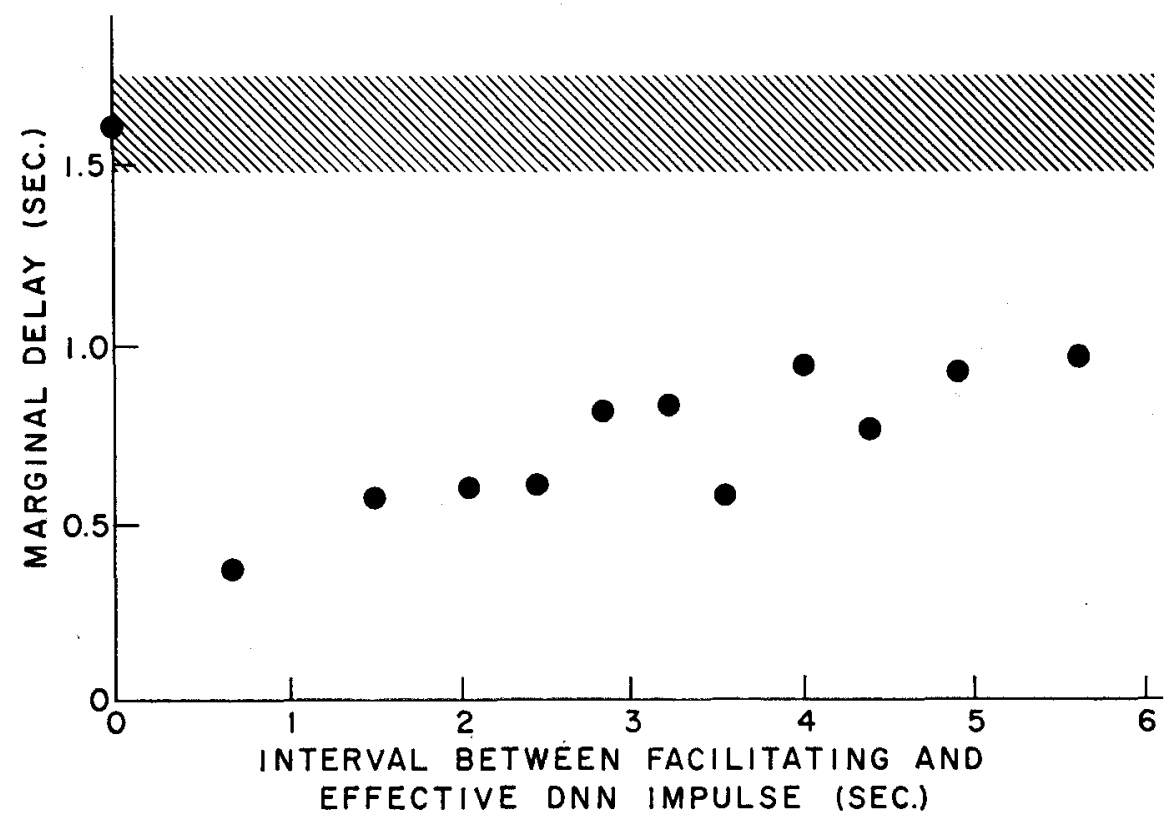

Fig. 6. Cassiopea. Marginal ganglion "delays" following paired DNN pulses. Point at zero interval is the mean delay for effective single DNN pulses; standard deviation of this mean value is shown by the horizontal band. (From Passano, 1965, Fig. 8).

In this experiment, one of the marginal pacemakers responded to a single DNN pulse $40 \%$ of the time; it always responded to a pair of pulses, however, even if they were as much as $8 \mathrm{~S}$ apart. Preparations vary widely in this respect; occasionally a preparation would never respond to a single DNN pulse, but even in these cases, the response to a pair of pulses was close to $100 \%$. In other preparations the ganglion would show a high level of responsiveness to single DNN pulses. 
Delay times for responses to pairs of DNN pulses are directly correlated with the time interval between the two pulses. When the interval is short, for instance, one $\mathrm{S}$, the average delay is also short ( $0.5 \mathrm{~S}$ or less). As the intervals get longer, so do the delays. Figure $5 \mathrm{~B}$ shows a pair of DNN pulses arriving $4.2 \mathrm{~S}$ apart; the delay in this case was $0.75 \mathrm{~S}$. When the intervals between DNN pulses increase to $8 \mathrm{~S}$ or so, delay times approach the single pulse value. Representative values of such delays are plotted against interval duration in Fig. 6.

In scyphomedusae, as with the hydromedusae, there is also another parameter of pacemaker state, the initiation of multiple pulses. There are two kinds of multiple firings in scyphomedusae, a train of fairly rapid GFNN pulses, and the production of very rapid pairs of GFNN pulses. Trains are a typical response to multiple DNN pulses, and give rise to a rapid series of swimming contractions of maximum strength. This is the typical behavioral response to prodding. A train of 6-10 DNN pulses will also cause, directly, a coordinated very slow contraction of the muscle sheet of the oral arms in Cassiopea, elevating them above the subumbrella. This direct muscular response to multiple DNN pulses takes a minute or more, so that it is much slower to be effected than the GFNN pacemaker response.

The very rapid pulse pairs occur frequently both with spontaneous firing as well as with DNN induction. They are particularly characteristic of Cyanea, where they can occur in up to half of all GFNN pacemaker outputs, but they also are found in Cassiopea (Passano, 1965). The interval between these rapid pairs (ca. $275 \mathrm{mS}$ ) is long enough in Cyanea to exceed the refractory period of the nerve net, but within the absolute refractory period of the effector, the subumbrellar striated muscle. The second pulse is thus transmitted across the subumbrella but seems to have no effect on the effector. In Cassiopea the second of such pairs usually occurs within the refractory period of the nerve-net, so it is suppressed (see PASSANO, 1965, Fig. 2 and accompanying text).

If such a very rapid pair occurs, it resets all of the other pacemakers. Frequently, however, a single GFNN pulse will trigger a second single pulse at another rhopalium after a brief interval (such as $295 \mathrm{mS}$ ). These pair interval times for both 'two out' and 'in-and-out' pairs are each remarkably consistent for each rhopalial pacemaker, yet are not quite identical with each other even for the same rhopalium.

Why pairs? It is hard not to speculate that there must be some paired pacemaker structure associated with each rhopalium: HoRRIDGE (1956a) noted that there is“... .a marked bilateral symmetry. .." in the marginal ganglion of the Aurelia ephyra larva. K. N. PASSANo (personal communication) has found clusters of 5-7 neuron cell bodies on each side of the rhopalial shaft in small Cyanea which may correspond to HoRRIDGE's type A cells (1956a). If each of these cell groups is a GFNN pacemaker, it would provide two closely coupled pacemaker sites in each rhopalium. HORRIDGE (1956a) hypothesized that what he termed "B cells" near to the statocyst at the end of the rhopalium were the pacemaker, but this seems unlikely to me since $I$ have had 
preparations continue to show pacemaker output after the outer half of the rhopalium had been excised.

Following passage of a GFNN pulse over the subumbrellar muscle sheet at $45 \mathrm{~cm}$ per $\mathrm{S}$ the muscle gives a strong smooth contraction. The time delay before muscle contraction varies from coronal to radial muscle, so that in both species the marginal muscles contract long before the central muscle blocks, in response to the same nerve impulse. The strength of the contraction is a classic example of facilitation (BULLOCK and HORRIDGE, 1965); it depends almost entirely on the time interval between successive GFNN pulses, with maximum strength for pulse pairs just longer than the muscle refractory period. But in certain cases the contraction is clearly asymmetrical, so that the animal is steered. This is most readily demonstrated by following successive contractions after the jellyfish has been tilted out of a normal vertical position. The animal "rights itself" by these asymmetrical contractions. It is generally assumed that the asymmetrical tilt preferentially excites the appropriate rhopalia (lowest or highest?) and that this pacemaker location somehow leads to the asymmetrical response. Horridge suggested (1956b) that the DNN also innervates the swimming muscles, and that the GFNN pacemaker initiates a DNN impulse as well as a GFNN pulse. Since the DNN conducts at $1 / 3$ the velocity of the GFNN such a dual innervation mechanism could only affect the nearby muscles before they responded to the GFNN pulse and became refractory. But as I have already noted there is no evidence supporting and much evidence denying DNN output from the rhopalia, so that HORRIDGE's suggested explanation of the righting response has no experimental basis. What might resolve this problem would be a way to identify the lead GFNN pacemaker under reasonably natural experimental conditions with whole animals, as well as simultaneous DNN recording.

The DNN does have several roles in controlling scyphozoan behavior. It coordinates tentacle activity. It triggers (but presumably does not coordinate) very slow manubrial reflexes. It provides a common sensory input to the marginal pacemakers to augment the GFNN-coordinated swimming activity in Cassiopea and Cyanea, although much of the pacemakers' sensory input - light, gravity, chemical sense(?)seems to be separate for each rhopalium and is not through-conducted across the entire animal. In the ephyra larva of Aurelia (Horridge, 1956a) and in the adult coronate medusa Nausithoe punctata (HoRRIDGE, 1956b) DNN pulses inhibit the GFNN pacemaker while producing feeding movements of tentacles and manubrium. Yet the DNN can carry on these disparate roles simultaneously by the simplest code imaginable; for example, in Cyanea: a single pulse acts on a tentacle but is less effective elsewhere; a pair of pulses excites marginal pacemakers,; a slow train of pulses can cause the manubrium to respond.

It has recently been possible to record consistantly from individual GFNN neurons (PATTON and PASSANO, 1972, 1974), in Cyanea, using conventional microelectrode pipette technique while observing with an inverted microscope. A carefully im- 
mobilized piece of muscle-free subumbrellar tissue just central to the rhopalium is used for this experiment. Slender tissue bridges connect this muscle free area to two blocks of subumbrellar muscle tissue. We can stimulate on either muscle area, and note the spread of the contraction wave up to the muscle free zone and then on the far side of it. With the intact rhopalium included, the preparation also shows spontaneous GFNN pulses. Tentacle stimulation gives DNN pulses without accompanying GFNN excitation.

With this preparation, we have confirmed HorRIDGE's finding (1945) of nonpolarized conduction in the GFNN. A single pulse is recorded for every spread of excitation, irregardless of direction, although the pulse shape is complex (Fig. 7) and varies according to direction. Our present findings disprove my own earlier claim (1958) for intermittent activity by elements of this nerve-net. That interpretation must now be considered erroneous, perhaps having been caused by minute tissue movements and the resultant microelectrode displacement.

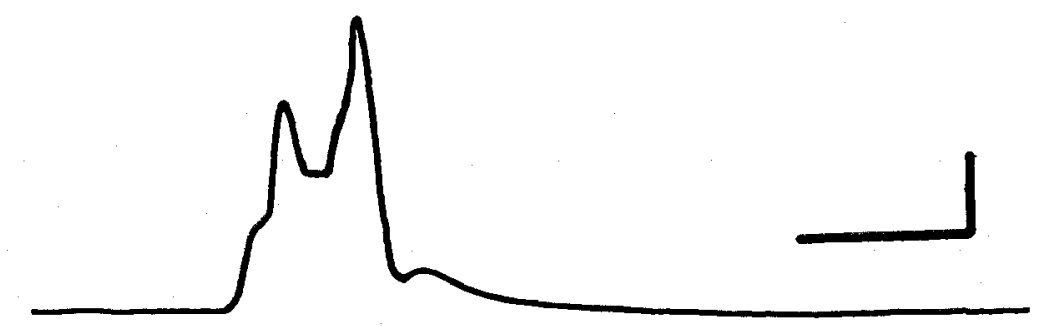

Fig. 7. Cyanea. Nerve pulse recorded from the cell body of an individual GFNN neuron; calibration 5mV, 10mS. (From PatTon and Passano, 1974).

However, several of our findings are so unexpected that we wonder if we have interpreted them correctly. First is the question of the resting potential. When the microelectrode tip is advanced into the ectodermal epithelial layer no electrical correlate of the GFNN pulse is seen unless the electrode is made to penetrate a large neuron cell body. When we make such a penetration, we record a small (less than $15 \mathrm{mV}$, usually a few $\mathrm{mV}$ ) resting potential whose sign may be either negative or positive to the cell surround! We have not found conventional resting potentials of the order of -50 to $-70 \mathrm{mV}$. Yet dye injections through the microelectrode show that neuron penetrations are achieved when we get this small, variable resting potential and with it the recording of GFNN pulses.

The second unexpected finding is the shape and complexity of these pulses. Figure 7 shows a typical pulse of the more complex sort. The entire pulse lasts about $9 \mathrm{mS}$, and can be subdivided into 4 or 5 component "spikes". The complex pulses are consistent from one pulse to the next in one specific direction of conduction, but elements of the pulse do shift or drop out in trains of pulses. Other recordings show simpler pulses. 
We interpret these pulses as being the result of postjunctional local excitation at the points of contact between the neurites of the GFNN. This activity, summed, spreads along the neurite past the cell body where we are recording. There is no evidence of an action potential in this non-decrementally conducting network. In fact, the intracellular pulses that we record are somewhat like those recorded by surface electrodes (Fig. 5), although an order of magnitude shorter. But we only record these GFNN pulses with microelectrodes when we are within the cell body. There has been nothing comparable to hydromedusan's epithelial pulses and we have not recorded any DNN pulses. Unexpected as our findings are, we must conclude that conduction in the GFNN of Cyanea, presumably conduction in the GFNN of other scyphomedusae, and perhaps scyphozoan nerve conduction in general, occurs in the absence of neurite action potentials, by cells without "ordinary" resting potentials.

\section{Discussion}

It is evident that there are both major similarities and distinct differences between Sarsia as a representative hydromedusa, and Cyanea or Cassiopea as representative scyphomedusae. The two classes of coelenterates have maintained remarkably similar "life-styles" in spite of the extreme length of geological time during which they have been separated. Compare the divergence of modern-day ctenophores (about whose fossil history little is known) to the convergence, or at least continuing similarity, of these two types of coelenterate jellyfish. In their behavior, such as food gathering or locomotion, they are very similar, whereas the ctenophore is different from either, set apart with a different behavior although occupying much the same ecological niche.

In the control systems underlying their behavior there are also many basic similarities between these two types of medusae. For example, a single nerve impulse coming from any one of a number of potential pacemaker sites is conducted rapidly around the subumbrellar ectodermal musculature, causing a powerful coordinated muscle contraction that forces a jet of water from the subumbrellar cavity to move the jellyfish ahead. This single nerve impulse (called the GFNN pulse in scyphomedusae and the SP in hydromedusae) resets the other potential pacemakers. And in both forms the pacemakers are under the influence of a second type of pulse, conducted on a separate pathway. In both cases the second pulse type excites the pacemaker after a significantly long time interval called the delay. If the second pulse type fails to cause the pacemaker to fire, it still sets up a sort of facilitation in the pacemaker so that the delay after another pulse is shorter. This state of facilitation gradually decays, as does the tendency to respond to the second pulse, even though these two effects have unequal rates of decay.

Certain aspects of this comparison between "delays" in the two jellyfish forms are illustrated by Fig. 8. The upper histograms show the more homogeneous responses to the second of a pair of pulses 1 to $3 \mathrm{~S}$ apart ("facilitated") while the lower histograms 


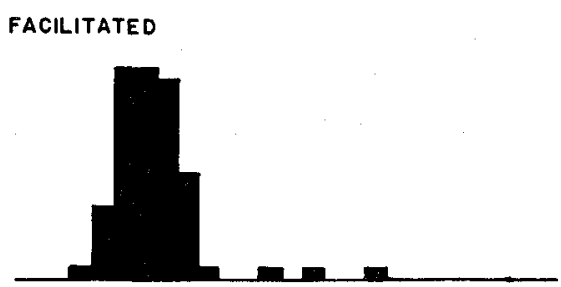

FACILITATED
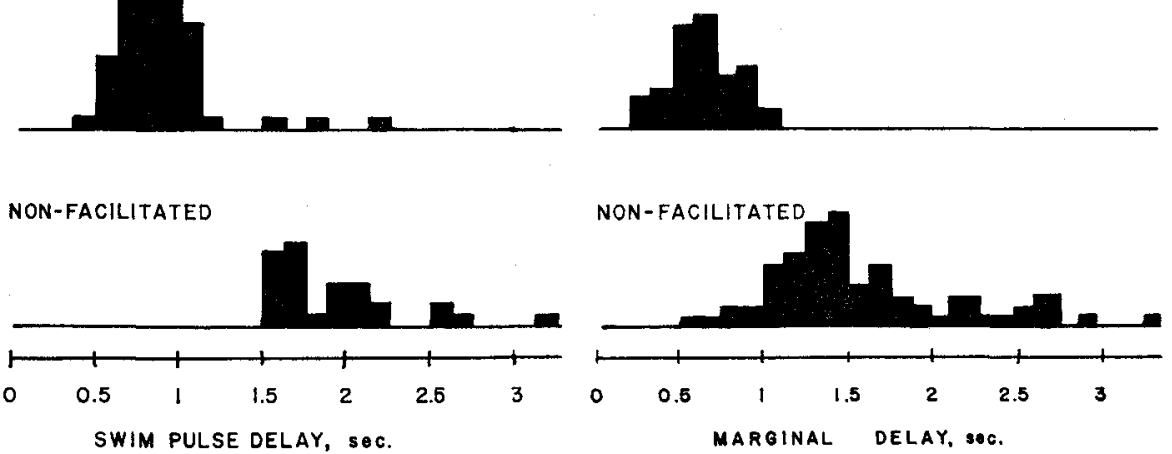

Fig. 8. Medusae pacemaker delay values, facilitated vs. non-facilitated, compared between the two classes of jellyfish.

show the longer, and more variable delays following single pulses. The basic similarities between these delays from the two types of medusae are striking. Note, however, that occasionally the response to the second of a pair of MPs in the swim pacemakers of Sarsia has the delay time characteristic of a single pulse ("non-facilitated") response, as if the first MP failed to facilitate. There is no evidence of a comparable failure of the first of a pair of DNN pulses in Cassiopea.

In Fig. 9 and Fig. 10, preliminary and tentative block diagrams of the behavioral control mechanisms of Scyphomedusa and Hydromedusa are given in order to permit a more general comparison between the two forms. In spite of the evident similarities, two fundamental differences exist: 1) the through-conducting system that extends everywhere in the Hydromedusa is non-nervous epithelial conduction, whereas in the Scyphomedusa it is the nervous DNN; 2) while Hydrozoa have multiple interacting pacemaker systems, the Scyphozoa have only one pacemaker system. Are these two differences connected? An advantage for the multiple pacemaker organization is that one of the systems can serve to set the level of arousal, or activity state, while the overt system controls the primary effector mechanism. This is especially important for an organism whose biology requires quite regular, repeated activity, as is true of a planktonic swimmer, yet whose habitat also has both circadian variation (light, food organisms, predators (?)), and irregular components (temperature, wave action, etc.). Two pacemaker systems permit two dissimilar patterns superimposed on one another, yet both of them can be free of the "general sensory input" role taken on by epithelial pulse conduction. The result of the hydrozoan forms having epithelial conduction which the scyphozoans do not possess is that the former can develop a fundamentally 
more sophisticated control complex within the restraints of a nervous organization with so few separate pathways. Thus the hydromedusae have a larger and more varied behavioral repertoire, for they have three distinct superimposed elements, epithelial, MP and SP pulse conduction pathways. The first can be responsible for gathering in to the "central" nervous system generalized sensory input, freeing the MP system for another role. In scyphomedusae with only two pathways throughout the animal, the DNN must subserve this sensory function, and nothing comparable to the MP pacemaker (or the RP system in Hydra or the NP system in Tubularia) can exist. There are several inputs (with different, specific or varying effects) on the SP pacemakers of Sarsia; each has direct or indirect feedback control on itself; these units also may interact with each other. Together they can build up a sizeable repertory of activity sequences, most of which are integrated throughout the entire organism. The

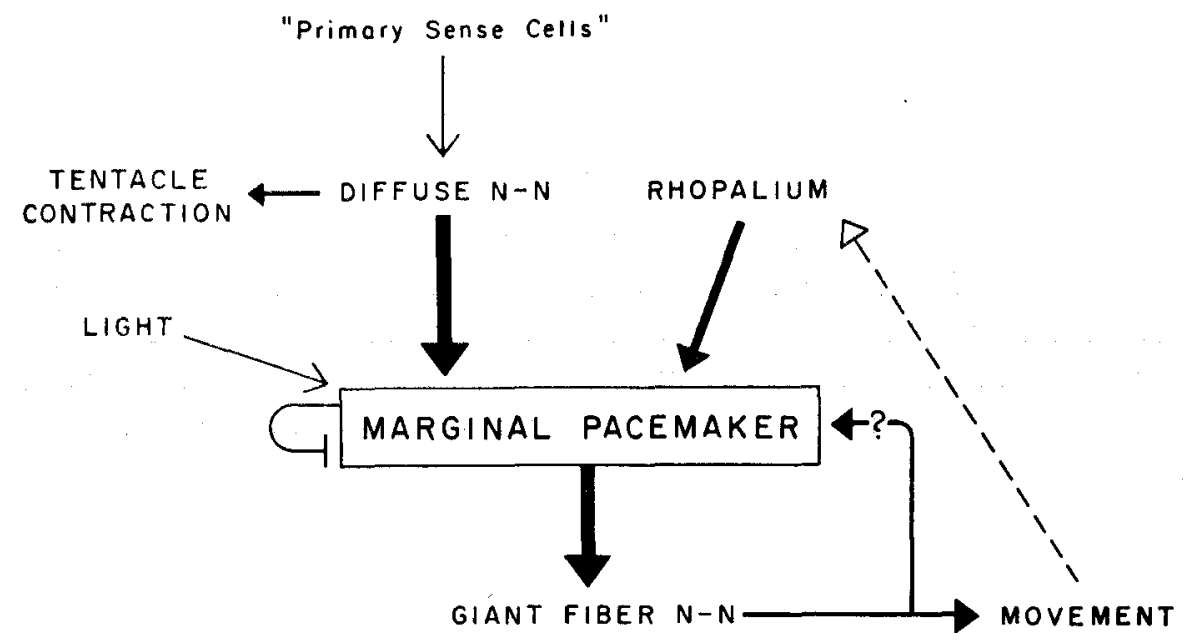

Fig. 9. Diagrammatic representation of the behavioral control mechanism of Cassiopea. Arrows show excitatory action; bars inhibitory action.

single pacemaker system of the scyphomedusae can show interesting interactions (as in the enigmatic rapid pair production) and can have varied multiple sensory inputs from the rhopalial sense receptors, but it does not show the rich behavioral complexity of a Sarsia since it has no hierarchy of endogenous pacemakers.

If the hydromedusae have gone further with their different control system, they may also have developed their nervous system by an independent evolutionary path. With "simple" conduction performed by the conducting epithelium, archeo-nerve cells' initial function could have been endogenous activity generation (PASSANO, 1963) or specialized conduction pathways between isolated blocks of effector cells (or pacemakers?) and the sensory epithelium (MACKIE, 1970). In the absence of epithelial conduction in Scyphozoa, nerve cells could have evolved to permit through-conduction 
as their primary function. Perhaps the difference between the classes is still reflected in their seemingly different mechanisms of neuroconduction. Clearly, much more work is required before there can be any assurance that our GFNN results are general for scyphozoan nerves or that MACKIE's (1973) Nanomia results hold for all hydrozoans. Somehow the DNN must be examined directly in this regard. Somehow it must be possible to record from the tentacular ganglion, in spite of my failure to do so in two summers of effort.

Eventually neurons evolved chemical transmission and (because of chemical synapses?) polarized junctions. In coelenterates there is good evidence for the existence of polarized junctions, although it has not as yet been verified by direct intracellular recording. The one-way actions of MPs on the SP pacemaker, or of DNN

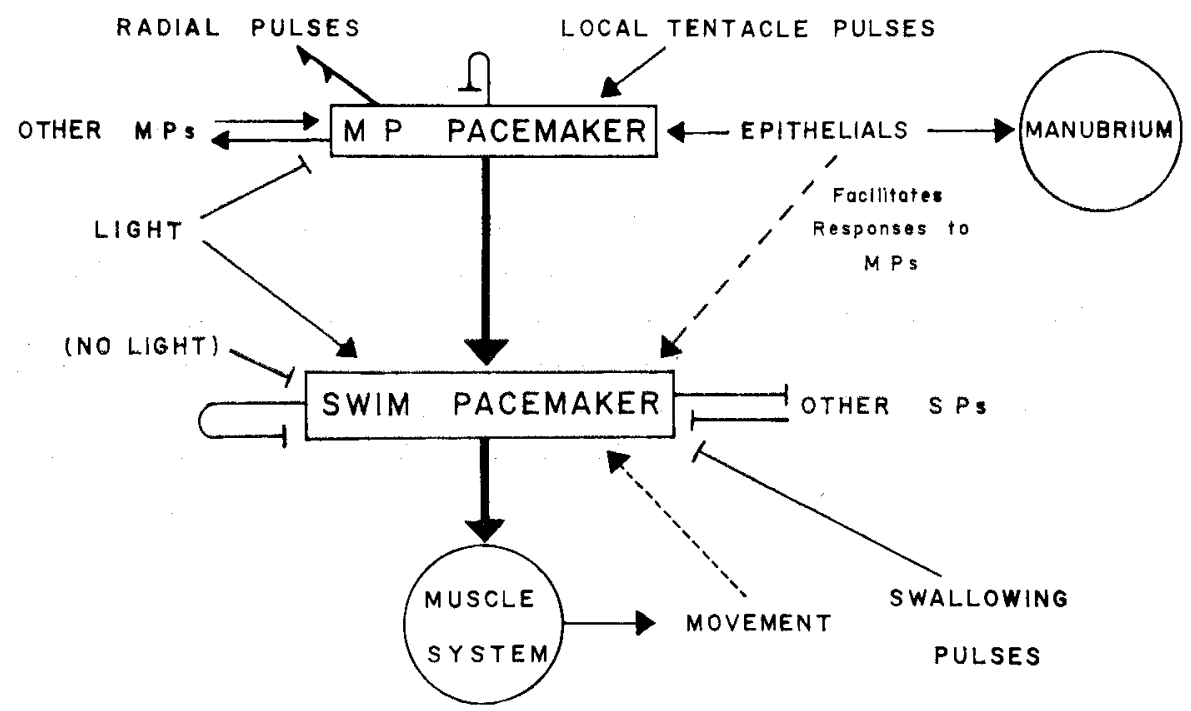

Fig. 10. Diagrammatic representation of the behavioral control mechanism of Sarsia. Arrows show excitatory action; bars inhibitory action.

pulses on the scyphozoan marginal pacemaker, are examples of this. But chemical, polarized synapses have not been demonstrated in coelenterates. There is no example of polarized synapses between different conduction pathways without a pacemaker intermediate! Neither nerve-net in the scyphomedusan subumbrellar ectoderm communicates with the other net save at the one-way connection at the marginal ganglion. The two nervous conduction pathways in the Sarsia marginal nerve ring are entirely separate. It is interesting that the phylum has evolved (separately?) several cases of pairs of nerve conduction pathways, but never more than two. The specific addressing of coelenterate nerve-net units is restricted to two addressees. When there are more than two pathways, there is reason to suspect non-nervous conduction.

These suggestions seem to contradict the very obvious similarities of pacemaker 
function that $I$ have repeatedly emphasized in this paper. If the nervous system of the two types of jellyfish are the result of convergent evolution it is all the more remarkable that their pacemakers are so similar. Coelenterate facilitation coding, whether the absolute type originally described by PANTIN (1935a) or the relative facilitation that shortens delay times in both jellyfish types here, would thus either reflect some fundamental functional unity of coelenterate design, or else be a surprising coincidence. Rather than the latter, it seems more fruitful to postulate that facilitation coding is a property associated with the development of the polarized synapse and/or the endogenous activity locus. It is worth recalling that a suggestion of patterned spontaneous "after-discharge" is even found occasionally at the "classic" facilitation site of the Calliactis sphincter neuromuscular junction (PANTIN, 1935b). Until it becomes possible to probe within the coelenterate pacemaker to discover both the functional and the morphological basis of this activity, it will not be possible to answer this question: how basic is the pattern of excitation, inhibition, long time delays, time facilitation, paired firing, rhythmic output, etc., to the coelenterate pacemaker? Are the common properties discussed here peculiar to these animals and their distinctive nervous systems, or are they common to all metazoans? Even if they are unique to the phylum, it may still be possible that these common properties have evolved separately from a pre-nervous ancestor, showing the limitations imposed by their common heritage (PANTIN, 1950). The answers to these questions are to be found in study of the physiological basis of their nervous coordinating systems.

Whether or not there is any merit in this suggestion of separate parallel and convergent evolution of the coordinating systems of the two medusa types, it is clear that their pacemakers show great similarities, that their conduction mechanisms are comparable but different in detail and that the hydromedusae, as exemplified by Sarsia, possess a much more elaborate control system (Fig. 10). It is an interesting mixture of specialized single purpose elements, and of multipurpose elements whose different functions are distinguished by simple coding. The SPs seem to have only one function-to activate the rapid powerful contraction of the subumbrellar coronal epithelial muscle cells for swimming. The MPs in contrast do many things: cause regional tentacle contractions, cause coordinated tentacle twitches, excite SP pacemaker bursts, synergize with epithelial pulses to cause the crumple reflex, induce radial contractions. Remarkably complex, "integrated" behavioral sequences can be built up in this way, as in the feeding transfer of copepod prey from tentacle to mouth or the intermittent "fishing" behavior of Sarsia in still water. The same sort of behavioral sequence is seen in the fishing behavior of the trachyline Gonionemus (YerKES, 1903) or in the "veronica" fishing filament display in Muggiaea (MACKIE and BoAG, 1963), a small calcophoran siphonophore.

The comparison of these two jellyfish types illustrates both the limitations and the complex capabilities of their restricted, yet specialized, nervous system. It shows how the addition of another element can enrich the behavioral capabilities of the 
morphotype considerably. The comparison, finally, suggests that the two classes may have evolved their behavioral controls separately.

\section{Summary}

The two types of jellyfish, the hydromedusae and the scyphomedusae, have evolved similar behavioral control systems involving nerve-nets and specialized receptors.

Both types possess endogenous pacemakers for one conduction system which are under excitatory control by another such system. If a stimulating pulse is ineffectual, it still facilitates the response to a second pulse by shortening the time interval between the arriving stimulus and the response output. This facilitation state gradually decays over many seconds.

Epithelial conduction gives the hydromedusae a third conduction path, which permits these animals to have two pacemaker systems arranged in a hierarchy. The subordinate system is entirely dedicated to generating periodic swimming movements, but the superior pacemaker system serves several functions. Epithelial conduction is not found in scyphomedusae and they have only one pacemaker system, dedicated to swimming. It is suggested that the two classes may have evolved their behavioral controls separately.

\section{REFERENCES}

Bullock, T. H. and G. A. Horridge. 1965. Structure and function in the nervous systems of invertebrates. W. H. Freeman and Co., San Francisco and London.

EIMER, G. H. T. 1874. Ueber künstliche Theilbarkeit von Aurelia aurita und Cyanea capillata in Physiologische Individuen. Ber. Physik. -Med. Ges.. Wurzburg, N. S. 6: 137-161.

Fränkel, G. 1925. Der statische Sinn der Medusen. Z. Vergleich. Physiol. 2: 658-690.

Fraser, J. H. 1969. Experimental feeding of some medusae and chaetognatha. J. Fisheries Res. Board Can. 26: 1743-1762.

GLADFelter, W. B. 1972. Structure and function of the locomotory system of Polyorchis montereyensis (Cnidaria, Hydrozoa). Helgolaender Wiss. Meeresuntersuch. 23: 38-79.

Hernandez-Nicaise, M.-L. and L. M. Passano. 1967. A physiological analysis of the feeding behavior of Sarsia tubulosa (M. SARS), a hydrozoan jellyfish. Am. Zoologist 7: 727.

HorridGe, G. A. 1954. The nerves and muscles of medusae. I. Conduction in the nervous system of Aurellia aurita LAMARCK. J. Exptl. Biol. 31 : 594-600.

Horridge, G. A. 1955. The nerves and muscles of medusae. II. Geryonia proboscidalis Eschscholtz. J. Expt1. Biol. 32: 555-568.

Horridae, (G.) A. 1956a. The nervous system of the ephyra larva of Aurellia aurita. Quart. J. Microscop. Sci. 97: 59-74.

HoRRIDGE, G. A. 1956b. The nerves and muscles of medusae. V. Double innervation in Scyphozoa. J. Expt. Biol. 33: 366-383.

Hyman, L. H. 1940a. The Invertebrates: Protozoa through Ctenophora. McGraw-Hill Book Co., Inc., New York and London.

Hyman, L. H. 1940b. Observations and experiments on the physiology of medusae. Biol. Bull. 79: $282-296$. 
Josephson, R. K. 1961. Repetitive potentials following brief electric stimuli in a hydroid. J. Exptl. Biol. 38: 579-593.

Josepirson, R. K. 1962. Spontaneous electrical activity in a hydroid polyp. Comp. Biochem. Physiol. 5: 45-58.

Kass-Simon, G. 1973. Transmitting systems in Hydra. Publ. Seto Mar. Biol. Lab. 20 (Proc. Second Internat. Symp. Cnidaria): 583-594.

MACKIE, G. O. 1965. Conduction in the nerve-free epithelia of siphonophores. Am. Zoologist 5: 439-453.

MACKIE, G. O. 1969. Neurological complexity in medusae: a report of central nervous organization in Sarsia. In: First International Symposium on Zoophylogeny, Salamanca, Spain, 1969. Publ. Univ. of Salamanca, Salamanca.

MACKIE, G. O. 1970. Neuroid conduction and the evolution of conducting tissues. Quart. Rev. Biol. 45: 319-332.

MACKIE, G. O. 1973. Report on giant nerve fibres in Nanomia. Publ. Seto Mar. Biol. Lab. 20 (Proc. Second Internat. Symp. Cnidaria): 745-756.

MACKIE, G. O. and D. A. BOAG. 1963. Fishing, feeding and digestion in siphonophores. Pubbl. Staz. Zool. Napoli 33: 178-196.

MACKIE, G. O. and L. M. Passano. 1968. Epithelial conduction in hydromedusae. J. Gen. Physiol. 52: $600-621$.

Mackie, G. O., L. M. Passano and M. Pavans de Ceccatty. 1967. Physiologie du comportement de 1'hydroméduse Sarsia tubulosa Sars. Les systèmes à conduction aneurale. Compt. Rend. 264: $466-469$.

MaYer, A. G. 1906. Rhythmical pulsation in scyphomedusae. Carnegie Inst. Wash. Publ. No. 47.

MAYer, A. G. 1910. Medusae of the world. 3 vol. Carnegie Inst. Wash. Publ. No. 109.

Pantin, C. F. A. 1935a. The nerve net of the Actinozoa. I. Facilitation. J. Exptl. Biol. 12: 119-138.

Pantin, C. F. A. 1935b. The nerve-net of the Actinozoa. III. Polarity and after-discharge. J. Exptl. Biol. 12: 156-164.

Pantin, C. F. A. 1950. Behaviour patterns in lower invertebrates. Symp. Soc. Exptl. Biol. 5: 175195.

Passano, K. N. and L. M. Passano. 1971. The endodermal nerve net of Scyphozoa. J. Morphol. 133: $125-144$.

Passano, L. M. 1958. Intermittent conduction in scyphozoan nerve nets. Anat. Record 132: 486.

Passano, L. M. 1963. Primitive nervous systems. Proc. Nat. Acad. Sci. U.S. 50: 306-313.

Passano, L. M. 1965. Pacemakers and activity patterns in medusae: homage to Romanes. Am. Zoologist 5: 465-481.

Passano, L. M., G. O. Mackie and M. Payans de Ceccatty. 1967. Physiologie du comportement de 1'hydroméduse Sarsia tubulosa Sars. Les systèmes des activités spontanées. Compt. Rend. 264: 614617 .

Passano, L. M. and C. B. MuCullough. 1962. The light response and the rhythmic potentials of Hydra. Proc. Nat. Acad. Sci. U.S. 48: 1376-1382.

Passano, L. M. and C. B. MCCullough. 1963. Pacemaker hierarchies controlling the behaviour of hydras. Nature 199: 1174-1175.

Patton, M. L. and L. M. PASSANo. 1972. Intracellular recording from the giant fiber nerve-net of a scyphozoan jellyfish. Am. Zoologist 12: (3) xxxv.

Patton, M. L. and L. M. Passano. 1974. Nerve impulses and resting potentials in a jellyfish nervenet. In preparation.

Romanes, G. J. 1885. Jelly-fish, star-fish and sea-urchins, being a research on primitive nervous systems. International Scientific Series Vol. 49. D. Appleton and Co., New York.

Russell, F. S. 1970. The medusae of the British Isles. II. Pelagic Scyphozoa with a supplement to the first volume on hydromedusae. Cambridge University Press, London and New York.

WERNER, B. 1963. Effect of some environmental factors on differentiation in marine Hydrozoa, 
with a note on their evolutionary significance. Ann. N.Y. Acad. Sci. 105: 461-488.

YERKES, R. M. 1903. A study of the reactions and reaction time of the medusa, Gonionema murbachii to photic stimuli. Am. J. Physiol. 9: 279-307.

\section{DISCUSSION}

TAMAsIGE: Do you think the giant nerve net system exists also in Scyphomedusae and Anthomedusae?

PASSANO: I do not believe that there is an analogous nerve net, in Anthomedusae, to the Scyphomedusan GFNN.

Yoshida: Dr. MACKIE has shown in a hydromedusa that the large and the small nerve fibers exist in the nerve ring. Do you think that the same kind of difference in function as you mentioned in scyphozoan nerve net exists in the nerve ring system?

PASSANO: I am unable to identify the specific function or functions of the various sized nerve fibers in the marginal nerve ring, as to MP, SP or other conduction pathways. Nevertheless, I do not believe that any of the hydromedusan nerves function in the specialized way suggested for the GFNN.

MüLLER: When I was a student I had to learn that there is no decrement in any nerve. Do we have now to return to the old term decrement? With other words, did you reach any evidence that the impulses indeed decrease in amplitude when conducted?

PASSANO: Functionally, the GFNN conducts without decrement of any kind. Indeed, MAYER and others have had "entrapped waves" of GFNN pulses conducted in "doughnut preparations" for many hours or even days. But our results appear to show that the individual nerve cells of the GFNN are not conducting all- or none action potentials as nerve cells usually do. Rather, the individual units show varied, complex wave form pulses whose components appear to decrement in passage along the neurite like EPSPs.

WERNER: I learned with interest that from the point of neurophysiology the Anthomedusae are more advanced than the Scyphomedusae. Have you published this result before or will it come out just now? It should be of importance from the point of evolution.

Passano: I hope that this report will serve to express my opinion as to the more advanced nature of the hydromedusan behavioral control mechanism. 


\section{EXPLANATION OF PLATE I}

Sarsia tubulosa, approximately $1.5 \mathrm{x}$ natural size.

A. Quiet floating. B. In the midst of a swimming bout, with tentacles beginning to relax. C. The crumple, an escape reflex. D. Quiet sinking during prey transfer from tentacle to mouth. 


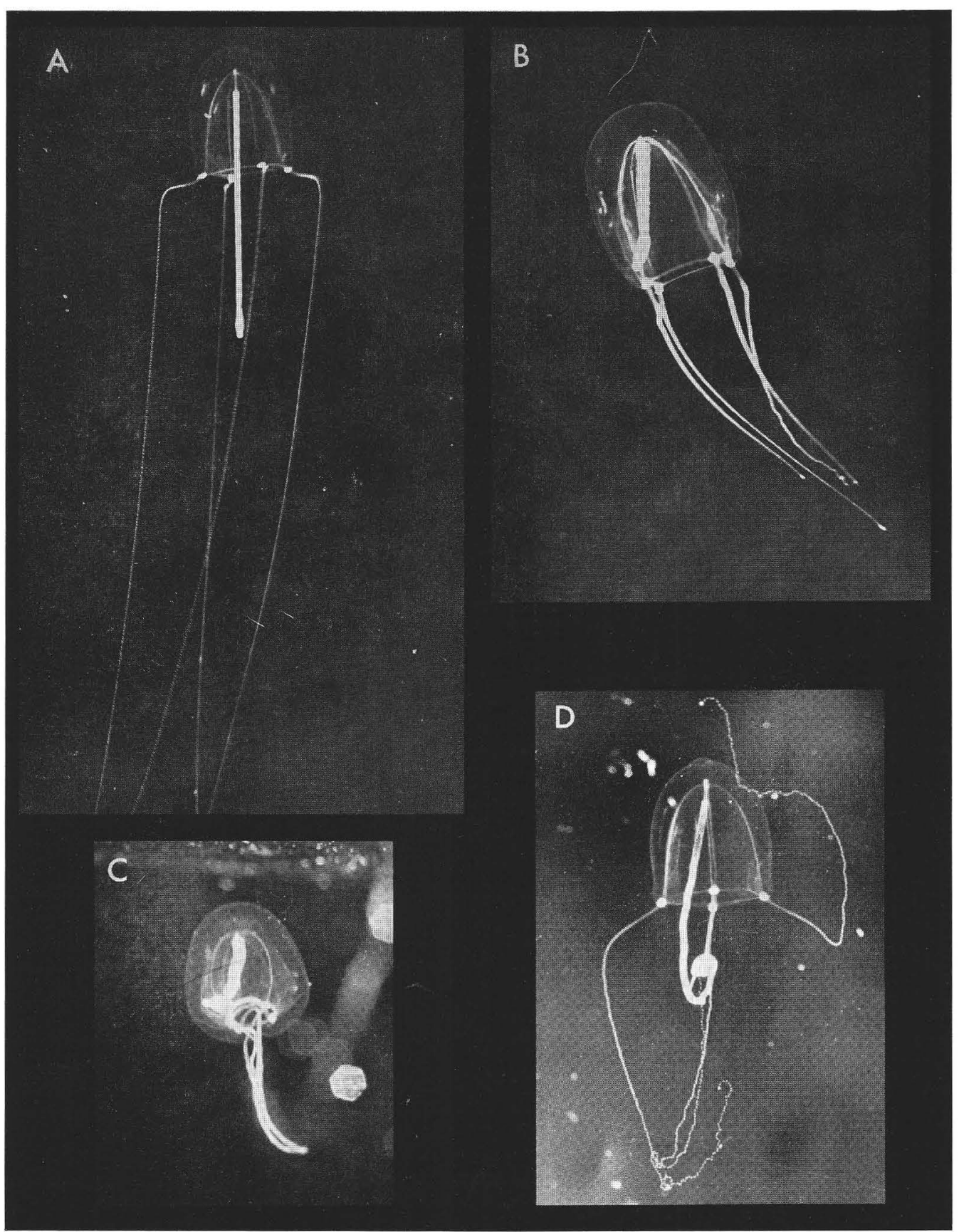

L.M. Passano: Behavioral Control Systems in Medusae 